\title{
Professional Ideas as Factor of Attitude towards Performed Activity
}

\author{
Evgeny Ivanovich $\operatorname{Rogov}^{1} \&$ Evgenia Evgenievna Rogova ${ }^{1}$ \\ ${ }^{1}$ South Federal University, Russian Federation \\ Correspondence: Evgeny Ivanovich Rogov, Sadovaya Street, 105/42, Rostov-on-Don, 344006, Russian \\ Federation. E-mail: profrogov@yandex.ru
}

\author{
Received: October 30, 2014 Accepted: November 31, 2014 Online Published: March 20, 2015 \\ doi:10.5539/ass.v11n8p233 \\ URL: http://dx.doi.org/10.5539/ass.v11n8p233
}

\begin{abstract}
Psychological aspects of functioning between professionals and amateurs are compared in the article. The differences between professionals and amateurs depending on ethnic characteristics, type of activity, professional environment itself are shown. It is revealed that ideas developed in the subject's consciousness towards carrying out activity define the peculiarities of its realization and form the demonstration of the corresponding behavior reactions. For professionals it is typical to render about activity as hard, difficult, intensive and responsible work that leads to the clear regulation of its aims and tasks, domination of professional behavior. Positive emotions, attitude towards activity as interesting, actively manifold, giving interesting contacts prevail in the ideas of amateurs, and it can cause revealing of carelessness, dreaminess, bustling.
\end{abstract}

Keywords: level of activity performance, professionalism, professionals, amateurs, image, professional ideas

\section{Introduction}

Separation of subjects of activity on professionals and amateurs at common level means just the simplest way to divide them on "good", skilful employees, with whom it is possible to deal with, and on "bad", "unprofessional" employees, whose results don't always suit. However in reality we more often come across confirmations that "amateurs" are people who are fond of their work while "professionals" aspire to earn or "to master" maximum money during minimum period of time. Preparation of professionals in high school requires to give more substantial answer on the question about the peculiarities of professional's activity.

Indeed in the aspect of public attitudes professional is first of all the person of waged labour, "skilled craftsman" who creates aloof product from him. By definition professional is the person openly accepting his specialization in society, having documental confirmation of his specialization and pretending for public recognition of skill level in his specialization. That's why the loss of work by the person making threat for satisfaction of fundamental necessities becomes "starting mechanism" for personal and existential crisis. In this case, J. Jacobson emphasizes, there appears the problem from which the person can't escape and which he can't decide in short period by usual ways (Yacobson, 1974). As D. Bukenuge, M. Buelens and others show, the speed of problem decision will depend on its connection with groups of values: conservative values and values opened to changes (Bouckenooghe et al., 2005, pp. 369-382). In this attitude the investigations of the unemployed by M. Jahoda are very demonstrative (Jahoda, 1981, pp. 184-191). In such foreshortening of regarding the amateur is in more profitable position as he is busy with his work when he wants and his well-being less depends on his passion to the performed activity.

It is essential to notice that division of subjects of activity on professionals and amateurs is used not in all professions. For example, such separation hardly can be found in architecture, cinema, music or cosmonautics. It stands to reason as in order to function in these fields it is necessary to have rather considerable financial and state support. In the strict sense of the word the definition of "amateur" means a person who knows his oats and not does his work duty-bound, i.e. being motivated by any other reasons.

Division on professionals and amateurs is present even in criminal unlawful activity. Criminal-professional is as a rule recidivist; at that recurrence is an indicator of definite specialization. Working as master a professional criminal knows his work very well and submits to it all his way of life. The life in places of confinement which usually provide him the highest status, privileged position doesn't frighten but even attracts him (Bandurka et al., 2002).

Sometimes amateurs are wrongfully identified with dilettantes (dilettante - is literally "delightful" (delectare lat. 
- delight). These terms separate planes meaning the attitude of the subject toward activity; in first case this is the person who likes his work, and in the second - a person who has very slight knowledge about this activity, half-educated person. That's why dilettante can't become amateur because the work for the soul also requires knowledge. By the way, in their love to the activity "amateurs" can anticipate "professionals" who don't always refer to their work with big passion: after all, it is said for nothing that the main difference of professional from amateur is that the amateur also likes all this.

Probably therefore in England it is considered that the most important place in man's life is occupied by what he is keen on in spare time and not what he does during work. The amateur attitude to the work is valued here more than special knowledge, and the amateur is esteemed more than professional. In the opinion of V. Ovchinnikov Englishmen possess enviable ability to get away from every day cares, to find a shelter from them in the sanctuary of private life. Namely they are the founders of amusing activities which they now call with the word "hobby" invented by them. Hobby for an Englishman is the only allowable way to demonstrate his individuality, attract attention to him and even openly boast of his own success (Ovchinnikov, 1980).

May be because of this reason many artists of the highest rank took offence to the very heart when they are called "professionals". Considering that the artist should always be a trainee and amateur they call plasterer and interior decorators professionals. From the other side, social images about amateurs often have not complimentary characteristics. So for example drivers-amateurs often show confusion even in simple situations, don't perform necessary actions or make extra ones instead of them. These images are mostly vividly realized in the image of driver-woman.

If we approach to this problem more correctly it would be well to single out objective psychological criteria of comparison of "professionals" and "amateurs". At that the comparison according to the level of education falls out from this row and will be hardly adequate: professionals in contrast to amateurs always have diplomas and licences but don't always correspond to them.

Very often advantages of professionals above amateurs are connected with formation of special structures of personality of "profi". In the opinion of V. D. Shadrikov in creation of complexes of professionally important qualities of the personality not only combinations of personality's features connected with the type of activity but also personal qualities professionally important for any type of professional activity take part ( Shadrikov, 1996). These are first of all responsibility, self-control, professional self-appraisal being an important component of professional self-consciousness, and some more specific features - emotional resistance, anxiety, attitude to risk. The peculiarities of nervous processes passing and some temperament features (extra-introversion, in particular) also become significant in many types of professional activity as they are the base for a number of professionally important qualities of personality - emotional resistance, anxiety, tendency to risk, even self-appraisal.

Comparing groups of professional and unprofessional traders with Kettle test T. V. Barlas and E. A. Utlandova revealed personal qualities of successful professionals which include analyticity of mind, high intellect level, self-discipline and intuition. At the same time the attitude to risk and the attitude to emotionality of professional market participants are double. Unemotional people who are not passionately involved in this activity can't stand all the difficulties of the profession. The ability to realize own and other's emotions allows to use them as one more reference point for the activity and one more distinction of the advantage above those who doesn't have it. May be there is no use to get rid of these qualities and vice versa - consider them, and in that case they will promote the success (Barlas \& Utlandova, 2008, pp. 91-98).

Similar results were received in the research of V. S. Sobkin and T. A. Feofanova who revealed direct interconnections between success and intuition of actors-amateurs. At that their success is mostly connected with the aspiration to excess the bounds of directly given - to understand meanings, connections, attitudes using intuition for it. Intuitive type probably possesses those features which allow amateurs to compensate the lack of professionalism while acting on stage. This fact explains the dependence of success of actors-amateurs from the ability for forecasting which permit them to overstep the limits of usual images about different phenomena of surrounding reality and play the role not due to the acquired skill but with the help of these qualities. The factors promoting success of actors-professionals (observation, imagination, congruence, adaptability, etc.) are to a great content connected with skills acquired by the professionals in the process of activity (Sobkin \& Feofanova, 2012).

Hence it can be supposed that long pursuit of adorable work by the amateur will form structure of personal qualities close to professional ones in a definite period of time. That's why the comparison of peculiarities of personality's parameter of amateurs with professionals will at best reveal their different evidence.

A big group of researchers see the difference between professionals and amateurs in conditions of activity 
passing. The same research of V. S. Sobkin and T. A. Feofanova assumes that the differences between actors amateurs and professionals are caused by different conditions in their creative activity (Sobkin \& Feofanova, 2012). Professional actors are more dependent from the producer and don't have possibility to choose play or role, but at that their repertoire is more rich and saturated. The actors-amateurs are more independent from external conditions but have less works in repertoire. Probably just therefore the person who is in hopeful mood and oriented for success is more resistant to the influence of negative factors of the environment (Kobasa, 1979, pp. 1-11).

In connection with that some researchers see distinguishing base professionalism in the specific character of activity performance. So comparing the behavior peculiarities of sportsmen in professional and amateur teams A. V. Chelpanov showed that in interaction professionals are mainly oriented for rivalry, while amateurs - for cooperation. During interaction in sport team activity mainly self-perfection values are updated in professionals and values connected with communication - in amateurs. Professionals show higher level of involvement of value communication sphere into performed activity in contrast to amateurs (Chelpanov, 2006). Steven Pressfield also concentrates attention on the difference of professionals and amateurs in the approaches towards activity considering that amateur only imitates his love to work while professional devotes him the whole time (Pressfield, 2013).

V. F. Ovsyannikov regards amateurishness as autonomous, necessary and productive area of people being and spirit. Regardless of fixed - destroyable opinion about amateurishness (of course, more or less conscientious) it has own status as a special type of perception; can reach reliable knowledge and effective social action in his own way. Among cognitive advantages of amateurs there is an increased level of activity motivation, its self-valuable, beyond utilitarian for the person character; freedom from burden of traditions and stereotypes of previous decisions of the definite social tasks; complete involvement of amateur's personality into his leisure activities (Ovsyannikov, 2004).

However, very often the activity of the professional and amateur takes place in similar conditions but the difference between their attitudes towards activity is obviously tangible. It compels to look for distinctions not in the conditions and external outline of the activity but in its internal structure reflected in self-consciousness.

The problem of professional self-consciousness becoming is one of the essential aspects of professional development during which a certain system of psychological images underlying in behavior regulation and finally in his life on the whole is formed in the person. Professional education, upbringing and storage of professional work experience, i.e. enclosure of the concrete professional content, changes the consciousness, makes it professional. When appeared, the professional self-consciousness becomes itself an important link in regulation both of current activity and development of the subject as a whole. The specific character of the world picture formed in man's head defined the depth and limits of the knowledge, emotional attitude and readiness of active action in it.

The subject can join in different types of activity which are not always significant and reflected in his consciousness with different depth (cooks meal but not a cook; drives a car but not a driver; makes wooden articles but not a joiner, etc.). In this case it means not professional but "serving" of subject's interests, "amateur" activity. The importance of regulating possibilities of "unprofessional" ideas is determined by the fact that some types of amateur activity directly take root in man's life and significantly influence on the safety of his being. So if tailor-amateur will cause client's irritation in case of poorly made order, the driver-amateur can kill the client. Inadequacy or mismatch of subject's images in attitude to directly performed activity which is not professionally significant for him can cause its poor performance, inadequate motivation and low level of self-control and responsibility.

From the other side many great discoveries in the science and in engineering in particular are made by amateurs whereas the actions of the professionals of the highest level sometimes lead to not simply bad results but to such catastrophes as a consequence of which many people pay their health and life itself (Ovsyannikov, 2004, p. 3).

Such position requires more precise learning of differences in the ideas of the performed activity in the consciousness of professionals and amateurs. In the process of personality development a special role is given to the ideas - just image-bearing knowledge becomes the main instrument of perception and foresight. E. Bern fairly noticed that the success of human activity depends on the fact how completely and precisely the idea corresponds to the reality (Berne, 1968). Singling out in the professional ideas structure the ideas about profession and personality of the professional, about himself as a future professional and about possible professional future, V. A. Semenova supposes that merging and interpenetration of these three components lead to the appearance of subject model of professional activity which is one of the most important regulators of 
personal and professional development of the person (Semenova, 2003). It is obvious that the components of the suggested model are available in amateurs too though they can have different evidence.

In the opinion of O. A. Knopkin professional ideas are not a simple combination of data about professional sphere but rather an image of activity structure "... which includes: activity goal accepted by the person; criteria of activity success; the program of performing actions; subjective model of significant conditions of the activity; information about really achieved results; decisions about corrections of activity system" (Konopkin, 1995, p. $34)$.

N. V. Dolgova examines professional ideas even wider - as detailed idea about mechanisms of behavior entire regulation. A false professionally-role idea has in its base impossibility of the person to understand his place in the present community of people and as a consequence disability to perform this or that role adequately (Dolgova, 2000).

Investigating professional ideas of future professionals - students, M. U. Kazaryan revealed the existence of two positions. First of all in professional ideas the characteristics necessary for the professional are united in the main groups which describe the peculiarities of creative, cognitive, active, civic, motivational, communicative and emotional sphere. Secondly, there is an idea about qualities which a professional should have (education, intellectual abilities, knowledge in professional sphere, responsibility, imperturbability and punctuality) and about those parameters which promote professional perfection (purposefulness, creative view on commonness, interpersonal skill, ability to learn himself and teach others, broad mind, aspiration for renovation of his knowledge) (Kazaryan, 2009).

Carried out review of literature testifies that the main content of personality's professional ideas is usually considered to be abilities and qualities of subject of activity from one side and peculiarities and parameters of professional activity from the other side because they embrace majority of factors which define personal changes of the specialist. In the individual consciousness the ideas undoubtedly have their own logic of the development and that confirms the necessity of this phenomena learning in professionals and amateurs in order to increase the level of activity productivity and to consider their motivation of success achievement. The person himself provides to a considerable degree the results and efficiency of the formed ideas.

At the same time the object of the activity and ideas about him as if escape researchers' attention though the essential role in achievement of professional's goal belongs to them. Just the condition of the object defines the direction of professional influence and becomes sphere of representation and vital activity of his personality for the object, and from the point of view of the activity can be regarded as the result of this activity. In the specialist's consciousness the object is represented as images which keep the most typical, important peculiarities of profession for the personality. The images of the ideas are appropriate result of sensible perception of the world, professional experience, they are inalienable property of specialist personality. The knowledge, which the professional has, gives him possibility to imagine the object of professional activity more complete, adequate, with a big amount of details, to compare him with the ideal. Later the objective approach becomes one of the main characteristics of professional view deformation when any person is estimated as the object of professional manipulations independent from situation (Chappell \& Di Martino, 2006).

Taking into account that professional ideas are the main element of group consciousness the attitude of the definite group towards this or that object is expressed in them; just they should be used to understand the differences in the activity of professionals and amateurs. The group plays the determining role in ideas forming: it fixes definite aspects of the idea; influences on the attitude to information; with the help of the ideas the group can vary the ways of manipulation by the facts, form its own identity, etc. (Dynamics of professional ideas during the period of social transformations, 2010).

All this predetermined the direction of this research of professional ideas peculiarities of professionals and amateurs which has been formed in different professions. From a great number of the surrounding us professions there were investigated the professional ideas peculiarities of professionals and amateurs in the activity of driving and in medical activity.

\section{Discussion}

The characteristics of driver's professional activity creates ideas about it as a hard, intensive work connected with emotionally volitional overworks, performed by skilled, determinate, self-disciplined persons. At the same time social ideas about the drivers of amateur level have by no means uncomplimentary characteristics as even in simple situations they very often display confusion.

So it can be supposed that driving activity is determined by the peculiarities of ideas which were formed in the 
person, and also it has interconnection with some behavioral characteristics.

In order to reveal ideas' regulating peculiarities of drivers with different level of inclusiveness and different attitude towards driving activity we carried out investigation with participation of working drivers (professionals) and persons occupied with driving on amateur level (amateurs).

For methodical support of the research the following psychodiagnostic procedures were used: questionnaire for drivers (Rogov \& Simchenko, n. d.); E. I. Rogov's questionnaire directed on learning of ideas peculiarities about driving activity, representing modification of semantic differential scale and allowing to define such factors of ideas as activity, evaluation, power, accuracy (Rogov \& Simchenko, 2013, pp. 59-66). For determination of the evidence of drivers' professionally important qualities we used questionnaire including four factors from personality test of R. Kettel: factor F (carelessness - anxiety), factor G (consciousness - unscrupulousness), factor M (dreaminess - practicality), factor Q3 (self-control, strong will - indifference). For measuring individual peculiarities of subjective control of different life situations we apply Rotter questionnaire.

According to the results of the survey with the help of the methodic "Questionnaire for drivers" it was found out that drivers-professionals $\left(\sum=1,6\right)$ possess such qualities as reliability, caution, carefulness in a greater degree than drivers-amateurs $\left(\sum=1,8\right)$, and that is the evidence of having high level of subjective control and responsibility. It on the whole corresponds to the suggestions about influence of driver's professionalism on behavioral characteristics.

The analysis of the drivers' ideas about their activity showed that high degree of evidence of such factors as power factor and accuracy factor is typical for images of drivers-professionals. The received data testify prevalence of professional ideas and their detailed representation in driver-professional's consciousness and also allow to make a conclusion that such categories as self-control, ability to keep to the established behavior line, independence from external circumstances and estimations, ability to reach the desirable, control the situation are important for respondents (Table 1).

Table 1. Average values of factors of ideas about driver's activity object

\begin{tabular}{lllll}
\hline Group & $\begin{array}{l}\text { Factor } \\
\text { estimation }\end{array}$ & power & activity & accuracy \\
\hline Professionals & 15,48 & 17,83 & 11,88 & 19,53 \\
Amateurs & 20,1 & 11,98 & 21,3 & 16,23 \\
\hline
\end{tabular}

At the same time it turned out that factor of estimation and factor of activity dominate in the ideas of drivers who drive on amateur level. It points to the disposition of this group of respondents to driving as positive, socially desirable moment bearing life satisfaction. Besides the ideas of drivers-amateurs are more variable, unusual and that can reflect in their activity, sociability, emotional sensitivity and impulsion.

As the received data show, the ideas of drivers with different direction and attitude to driving differ very much and probably cannot but effect on appropriate to them behavior line.

The data received by factors of Kettel's questionnaire (4 factors) revealed that such qualities as conscientiousness and practicality appear more at drivers-professionals than drivers-amateurs. It means that obligation, good conscience, discipline, developed responsibility feeling are more typical for drivers-professionals. They are more often guided by reality, orient themselves very well in life situations, and decide practical questions competently. It was also found out that drivers-professionals have serious and responsible attitude towards life and have high self-control of their behavior, and that is displayed in good organization and self-discipline, ability to control their emotions and behavior very well, to reach the set goals (Table 2).

Table 2. Average values of personality factors of Kettel test

\begin{tabular}{|c|c|c|c|c|}
\hline Drivers & $\begin{array}{l}\text { F } \\
\text { (carelessness) }\end{array}$ & $\begin{array}{l}\mathrm{G} \\
\text { (high } \\
\text { conscientiousness) }\end{array}$ & $\begin{array}{l}\text { M } \\
\text { (dreaminess) }\end{array}$ & $\begin{array}{l}\text { Q3 } \\
\text { (high self-control) }\end{array}$ \\
\hline Professionals & 4,88 & 6,95 & 5,2 & 7,18 \\
\hline Amateurs & 7,05 & 5,33 & 6,67 & 5,3 \\
\hline
\end{tabular}


In the group of amateur level drivers the received personal characteristics according to this test show their bigger carelessness and dreaminess. Moreover, in some cases they can display unconscientiousness and insufficient self-control of their behavior.

Hence the findings allow to say that drivers-professionals in comparison with amateurs possess more evident professional qualities: conscientiousness, discipline, developed responsibility feeling, high self-control.

According to the results of the methodic "Rotter's questionnaire" it is obvious that practically on all internality scales drivers-professionals have higher indexes than drivers-amateurs (Table 3). This fact let the professionals consider themselves more independent, determinate, fair and skillful in contrast to drivers-amateurs who characterize themselves as egoistic, dependent, irresolute, fussy, hostile, diffident, influenced by others. Among separate scales the evidence of internality domination in the area of failures and productive attitudes is indicative, and that testifies about more serious, responsible approach of respondents-professionals to the driving. It is probably connected with the aim of drivers-professionals at the fact that the vents occurring with them depend first of all from them (their competence, purposefulness, level of capabilities, etc.) and they are regular consequences of their actions and deeds.

Table 3. Average values by scales of Rotter's questionnaire

\begin{tabular}{|c|c|c|c|c|c|c|c|}
\hline \multirow[b]{2}{*}{ Drivers } & \multicolumn{7}{|c|}{ Internality scales } \\
\hline & $\begin{array}{l}\text { Internality } \\
\text { total }\end{array}$ & $\begin{array}{l}\text { Internality in } \\
\text { the field of } \\
\text { achievements } \\
\text { B }\end{array}$ & $\begin{array}{l}\text { Internality } \\
\text { in the } \\
\text { field of } \\
\text { failures }\end{array}$ & $\begin{array}{l}\text { Internality } \\
\text { in the } \\
\text { field of } \\
\text { family } \\
\text { attitudes }\end{array}$ & $\begin{array}{l}\text { Internality } \\
\text { in the field } \\
\text { of } \\
\text { productive } \\
\text { attitudes }\end{array}$ & $\begin{array}{l}\text { Internality in } \\
\text { the field of } \\
\text { interpersonal } \\
\text { attitudes }\end{array}$ & $\begin{array}{l}\text { Internality } \\
\text { in the } \\
\text { field of } \\
\text { health and } \\
\text { disease }\end{array}$ \\
\hline Professionals & 6,48 & 5,98 & 5,35 & 5 & 5,98 & 4,83 & 4,75 \\
\hline Amateurs & 4,8 & 5,43 & 4,35 & 4,85 & 4,8 & 5,3 & 4,98 \\
\hline
\end{tabular}

The research of the interconnection of drivers-professionals' personal characteristics with their ideas about driving with the help of Pirson correlation index (r) revealed negative connection between factor $F$ "carelessness - anxiety" and factor of ideas power $(\mathrm{r}=-0,435$, at $\rho \leq 0,01)$. It allows to contend that the domination of professional ideas leads to the decrease of drivers-professionals' carelessness, increase of their seriousness and self-control. And vice versa careless, impulsive behavior of professionals is connected with professional ideas in less degree. At the same time factor $\mathrm{F}$ of drivers-professionals is positively connected with the factor of ideas estimation ( $r=0,313$, at $\rho \leq 0,05)$, that gives the possibility to suppose rather high probability of having positive ideas about driving at careless, unconcerned behavior. It is quite obvious that in case of car driving such interconnection can increase the possibility of the accident.

The probability of negative results of drivers-amateurs within the frames of learning activity can be increased by the existence of positive correlation of factor M "dreaminess - practicality" with the factor of power of ideas about driving ( $\mathrm{r}=0,37$, at $\rho \leq 0,05)$, that allows to suppose strengthening, domination of unreal, fantastic ideas about driving. At the same time factor $\mathrm{M}$ of drivers-professionals is positively correlated with factor Q3 "high low behavior self-control" $(\mathrm{r}=0,381$, at $\rho \leq 0,05)$ in comparison with amateurs, and that let talking about real, close to reality content of their fantasies which are controlled by person's will.

During correlation analysis of interconnections between driving ideas values in amateurs group there was found out a stable connection between estimation and activity factors $(r=0,717$, at $\rho \leq 0,01)$. It means that professional-amateurs' ideas about active behavior at the wheel causing communication generates driving ideas as the carrier of positive, socially desirable characteristics.

Carried out correlation analysis discovered stable feedback between power and estimation factors of drivers-amateurs $(r=-0,321$, at $\rho \leq 0,01)$, that shows inhibitive influence of the idea about driving as intensive, requiring high will forces work on the receipt of positive emotions at the wheel.

It turned out that the connection between estimation and activity factors of drivers-amateurs $(r=0,717$, at $\rho \leq 0,01)$ is much higher than of drivers-professionals $(\mathrm{r}=0,351$, at $\rho \leq 0,05)$. This fact shows that the drivers-amateurs imagine driving as an active action stimulating communication, more often aware driving as the carrier of positive, socially desirable characteristics, they are more satisfied by it than drivers-professionals.

The analysis of drivers-professionals' correlation connections of total internality revealed the presence of 
negative interconnections with professional ideas by activity factor $(\mathrm{r}=-0,317$, at $\rho \leq 0,05)$ and estimation factor $(\mathrm{r}=-0,362$, at $\rho \leq 0,05)$. This data also prove the supposition that high self-control limits the mobility, dispersion of the ideas and doesn't promote appearance of the opinion about driving as a process giving pleasure and positive emotions.

It is worthy of note that the internality of drivers-professionals in the area of interpersonal attitudes is the center of connection with all other types of internality: with internality in the field of failures $(r=0,404$, at $\rho \leq 0,01)$, with internality in the field of family attitudes $(r=0,563$, at $\rho \leq 0,01)$ and with internality in the field of health $(r=0,456$, at $\rho \leq 0,01)$. This fact can be explained by the peculiarity of driving work - individual responsibility for all the events in the moving car. Coming into interpersonal contacts with surrounding people that supposes even distribution of responsibility between participants doesn't probably change the aims of drivers, and that is in a greater degree shown in the internality in the area of interpersonal connections. It is also confirmed by the fact that this type of internality is closely connected with total internality $(\mathrm{r}=0,433$, at $\rho \leq 0,01)$ and has correlation feedback with factor $F(r=-0,318$, at $\rho \leq 0,05)$.

It is interesting that the correlation analysis didn't find interconnections between internality values and other investigating values of drivers-amateurs, that can be the evidence about insufficient inclusiveness of self-control into ideas about driving and behavioral reactions.

High correlation connection between total internality scale and the scale of internality in the field of productive attitudes $(r=0,772$, at $\rho \leq 0,01)$ gives the possibility to talk that on the whole it is typical for the drivers of amateur level to take responsibility for the events in the situations connected with their productive attitudes but not with driving. The central, forming component of the subjective control of drivers-amateurs is the control in the field of achievements which is positively connected with internality in productive attitudes $(\mathrm{r}=0,577$, at $\rho \leq 0,01)$, and has negative interconnections with the scale of internality in family attitudes $(r=-0,583$, at $\rho \leq 0,01)$ and scale of internality in the field of failures $(\mathrm{r}=-0,513$, at $\rho \leq 0,01)$, that probably points at the meaning of these fields for satisfaction of necessity in the achievement.

Thus carried out research of the peculiarities of the attitude to driving activity by the drivers-professionals and drivers-amateurs let to make a conclusion that social ideas formed in the person's consciousness in the attitude to the performed activity determine the peculiarities of its performance and form the demonstration of the corresponding behavioral reactions. The idea about driver's activity as hard, intensive and responsible work leads to clear representation and domination of professional ideas in the consciousness of the driver-professional, and also makes the person display such professionally important qualities of drivers as self-control, ability to keep accepted behavioral line, independence from external circumstances and estimations, practicality, ability to reach desirable, to control situation.

The idea about driver's activity as interesting, actively different, generating communication, causing positive emotions can evoke carelessness, dreaminess, fussiness in drivers of amateur level. In some cases they can show uncertainty, hostility, unconscientiousness and insufficient self-control of his behavior.

The received data allow to make a conclusion that without preliminary formation of adequate professional ideas about mastering activity its acquirement can face serious difficulties.

The comparison of medical workers (professionals) and their patients (amateurs) became one more direction of the research. For defining differences in professional ideas between medical workers and patients we used questionnaire oriented on learning of professional ideas about object of activity (Table 4).

Table 4. Average values of ideas factors about object of activity of medical worker

\begin{tabular}{lllll}
\hline \multirow{2}{*}{ Group } & Factor & & & \\
& Estimation & Power & Activity & Accuracy \\
\hline Medical workers & 4,5 & 3,35 & 5,6 & 5,6 \\
Patients & 5,8 & 4,1 & 4,3 & 4,2 \\
\hline
\end{tabular}

The factor of "Image estimation" showing the level of respect attitude to the object from person's side possesses average values by indexes of medical workers group.

According to the results of medical workers group the factor "Image power" adopts low values, and that displays insufficient self-control of the object, dependence from external circumstances and estimations, inability to 
control situation. There were also revealed high values of medical workers by factor "Activity" showing activity and emotional response and factor "Accuracy" demonstrating accuracy and vividness of the object of profession.

By the received results high values of the factor "Image estimation" of profession prevail in the patients group describing the receipt of the profession, object and its awareness as the carrier of positive, socially desirable characteristics. Such factors as "Image power" showing self-control development, "Image activity" characterizing the level of object's and "Image accuracy" displaying accuracy and vividness in the object's consciousness possess average values based on the results of patients group.

Thus the accuracy of medical workers' ideas about the object of medical activity, profession is a little bit higher than patients'. Professional ideas of medical workers are characterized by sufficient integrity and clearness because they are directly absorbed in medical activity. The patients are guided by knowledge received only during a visit and also by the information available from mass media.

Some scales of the methodic TOBOL (type of attitude to the disease) were used for psychological diagnostic of attitude types. The attitude to the disease, treatment, doctor and medical staff, family, work (studies) refers to them. This methodic gives the possibility to diagnose the type of attitude to the disease based on the information about patient's attitude to a number of life problems and situations which are potentially the most significant for him. During interpretation of the received data the following results were revealed (Table 5).

Table 5. Average statistical values according to the methodic TOBOL

\begin{tabular}{lll}
\hline Group & Medical workers & Patients \\
\hline Harmonic & 6.2 & 3.9 \\
Ergopathetic & 11.1 & 6.2 \\
Anosognosic & 4.3 & 11.2 \\
Anxious & 3 & 2.7 \\
Hypochondriac & 3.3 & 3 \\
Neurasthenic & 1.1 & 1.7 \\
Melancholical & 2.9 & 1.5 \\
Apathetic & 3 & 1.1 \\
Sensitive & 7.2 & 4.7 \\
Egothentric & 2.8 & 2.7 \\
Paranoiac & 2.1 & 2.7 \\
Dysphoric & 1.7 & 2.6 \\
\hline
\end{tabular}

The leading types of attitude to the disease of medical workers are ergopathetic (11.1) and sensitive (7.2). The first type is characterized as "escape from the disease to work". These results allow to speak about very responsible attitude to work which is in some cases expressed even in more degree than till disease; about selective attitude to examination and treatment caused by drive to continue work; aspiration for keeping professional status by all means and possibility to continue active work in old position. The second type is characterized by the appearance of fears that surrounding people will feel pity, consider incomplete, fear to become a burden on family because of the disease, which can cause fluctuation of mood. According to the results of diagnostics the other types didn't enter a group of values exceeding minimum.

The anosognosic type of attitude to the disease (11.2) was revealed in patients' group. This type can be characterized as active shying away with thought about disease, its possible consequences up to denying obvious. In connection with this fact the refusal from medical examination and treatment, wish to "shift for oneself" and also unreasonably increased mood, dismissive, light-minded attitude to the disease and treatment are very often typical.

So after carried out research one can say that there are differences in types of attitudes to the disease between patients and medical establishments' employees. Medical workers prefer not to notice diseases absorbing into work, while patients are characterized by aspiration to shy away with thought about disease and its possible consequences.

For defining interconnection of such investigated characteristics as professional ideas about medical activity and types of attitudes to the disease taking into account that the distribution doesn't differ from normal there was 
used Pirson line correlation index.

It turned out that image activity factor negatively correlates with sensitive type of attitude to the disease ( $\mathrm{r}=$ -0.378 , at $\rho \leq 0.05$ ). In other words image activity factor is in the inverse dependence from appearance of fears that surrounding people will feel pity, fear to become a burden on family because of the disease. It allows to make a conclusion that the idea about medical activity object as sympathetic and open decreases the possible anxiety about unfavorable impressions which the information about disease can make on the surrounding people.

Image accuracy factor positively correlates with apathetic $(\mathrm{r}=0.409$, at $\rho \leq 0.01)$, melancholic $(\mathrm{r}=0.438$, at $\rho$ $\leq 0.01)$ and hypochondriac $(\mathrm{r}=0.355$, at $\rho \leq 0.05)$ types of attitudes to the disease. Therefore accuracy and vividness of profession image in person's consciousness is connected with the appearance of apathy towards outcome of the disease, results of treatment, unbelief in possible improvement and also excess concentration on subjective painful and other disturbing feelings.

Analysis of the interconnections received in the result of patients survey showed that image accuracy factor negatively correlates with paranoiac type of attitude to the disease $(r=-0.52$, at $\rho \leq 0.05)$. In other words, the higher the accuracy of doctor profession image of the patient, the lower the extreme suspiciousness and vigilance to the medicine and procedures.

Image estimation factor positively correlates with apathetic $(r=0.390$, at $\rho \leq 0.05)$ and melancholic $(r=0.386$, at $\rho$ $\leq 0.05$ ) types of attitudes to the disease. It shows that the level of respectful attitude to the object from person side is connected with complete unconcern to his destiny, outcome of the disease and results of treatment and also unbelief in recovery, possible improvement, and effect of treatment. Accepting the object of medical activity the patient is inclined to aware it as the carrier of positive, socially desirable characteristics and in a sense is satisfied by it, but at that the doubt in treatment success doesn't leave him even at favorable objective data and satisfactory state of health.

\section{Conclusion}

So the comparison of the combination of the received data allowed to determine that the ideas formed in the subject's consciousness towards performed activity define the peculiarities of its realization and form the demonstration of the corresponding behavior reactions. The findings testify the domination of professional ideas and their detailed representation in professional's consciousness and also let to conclude that such categories as self-control, ability to keep accepted behavior line, independence from external circumstances and appraisals, ability to achieve the desired, control the situation are important for respondents.

At the same time it turned out that the attitude to the work as positive, socially desired moment which gives life satisfaction prevails in the ideas of amateurs. Besides amateurs' ideas are more variable, unordinary, that can be reflected in their activity, sociability, emotional sensitiveness and impulsion.

Amateurs' ideas about activity are connected with activity and communication and generate images of the personality as a carrier of positive, socially desired characteristics. At the same time amateurs' orientation on getting positive emotions acts as a brake of ideas about activity as intensive, requiring great fiats of will in the work. That's why probably the amateurs are more satisfied with their work than professionals.

So it can be concluded that social ideas formed in the subject's consciousness towards performed activity define the peculiarities of its realization and form the demonstration of the corresponding behavior reactions. Professionals' ideas about activity as hard, intensive and responsible work lead to the clear evidence and domination of professional ides in the consciousness of professionals; and also make subject to show such professionally important qualities as self-control, ability to keep accepted behavior line, independence from external circumstances and appraisals, practicality, ability to achieve the desired, control the situation.

The idea about activity as interesting, actively different work generating communication, positive emotions can cause carelessness, dreaminess, bustling in the employees of amateur level. In some cases they can demonstrate uncertainty, hostility, unconscientiousness and insufficient self-control of his behavior.

The received data give the possibility to make a conclusion that without preliminary formation of adequate professional ideas about mastering activity its learning can face serious difficulties.

\section{References}

Bandurka, A. M., Bocharova, S. P., \& Zemlyanskaya, E. V. (2002). Legal psychology. Kharkov, National University of home affairs.

Barlas, T. V., \& Utlandova, E. A. (2008). Comparative-psychological peculiarities of traders professionals and amateurs. Applied legal psychology, 3, 91-98. 
Berne, E. (1968). A Layman's Guide to Psychiatry and Psychoanalysis. N. Y.: Simon \& Shuster.

Bouckenooghe, D., Buelens, M., Fontaine, J., \& Vanderheyden, K. (2005). The prediction of stress by values and value conflict. Journal of Psychology: Interdisciplinary and Applied, 139(4), 369-384. http://dx.doi.org/10. 3200/JRLP.139.4.369-384

Chappell, D., \& Di Martino, V. (2006). Violence at Work (3rd ed.). Geneva: International Labor Office.

Chelpanov, A. V. (2006). Value and communicative peculiarities of amateurs and professionals personalities in sport team activity (Master's thesis). St. Petersburgh.

Dolgova, N. V. (2000). The peculiarities of professionally-role ideas of public servants. Master's thesis. Moscow.

Dynamics of professional ideas during the period of social transformations. (2010). Rostov-on-Don.

Jahoda, M. (1981). Work, employment, and unemployment: Values, theories, and approaches in social research. American Psychologist, 36(2), 184-191. http://dx.doi.org/10.1037/0003-066X.36.2.184

Kazaryan, M. U. (2009). The ideas about a creative personality and a professional in juvenile age. Master's thesis. Moscow.

Kobasa, S. (1979). Stressful life events, personality and health: An inquiry into hardiness. J. Pers. and Soc. Psychol, 37, 1-11. http://dx.doi.org/10.1037/0022-3514.37.1.1

Konopkin, O. A. (1995). Psychological mechanisms of activity regulation. Moscow: Vympel.

Ovchinnikov, V. (1980). Roots of oak. Impressions and thoughts about England and Englishmen. Moscow: Mysl.

Ovsyannikov, V. F. (2004). Professionals and amateurs in history and theory of perception. Master's thesis. Kursk.

Pressfield, St. (2013). The War of Art: Break Through the Blocks and Win Your Inner Creative Battles War for creative: how to overcome internal barriers and start creating. Alpina publisher.

Rogov, E. I., \& Simchenko, A. N. (2013). The influence of social ideas about activity on the peculiarities of its realization. The Proceedings of South Federal University. Pedagogical Sciences, 2, 59-66.

Semenova, V. A. (2003). The peculiarities and formation of students' professional ideas in the educational field of pedagogical college. Master's thesis. Moscow.

Shadrikov, V. D. (1996). Psychology of person's activity and ability. Moscow: Logos.

Sobkin, V. S., \& Feofanova, T. A. (2012). To the question about diagnostics of actor's endowments: Social and psychological aspects. Sociology of education. Retrieved from http://www.socioedu.ru/node/257/

Yacobson, G. (1974). Programs and techniques of crises intervention. In American handbook of psychiatry. New York.

\section{Copyrights}

Copyright for this article is retained by the author(s), with first publication rights granted to the journal.

This is an open-access article distributed under the terms and conditions of the Creative Commons Attribution license (http://creativecommons.org/licenses/by/3.0/). 